\title{
The creation of a body donation program at Federal University of Juiz de Fora in Brazil: academic importance, challenges and donor profile
}

\author{
André Gustavo Fernandes de Oliveira ${ }^{1}$, Augusto Ferreira Gonçalves ${ }^{1}$, Júlia Nunes Soares ${ }^{1}$, \\ Letícia Henriques Neto Salgado ${ }^{1}$, Bruno Silveira Santana ${ }^{1}$, Matheus Venâncio Passos ${ }^{1}$, \\ Juliana Lopes de Oliveira Reis ${ }^{1}$, Gustavo Candiá Arantes ${ }^{1}$, Luís Filipe Sarmento Campos ${ }^{1}$, \\ Matheus Souza Carvalho ${ }^{1}$, Lucas Cotrim Furtado da Gama ${ }^{1}$, Alice Belleigoli Rezende ${ }^{1,2}$ \\ ${ }^{1}$ Department of Anatomy, Federal University of Juiz de Fora, Juiz de Fora, ${ }^{2}$ Department of Medical Education, Federal University of Juiz de Fora, Juiz
} de Fora, Brazil

\begin{abstract}
Dissection and human specimens study remain the gold standard method for teaching anatomy. Due to the increasing health science courses in Brazil, the traditional way of obtaining bodies for scientific purposes, the unclaimed ones, became insufficient. In addition, this source is no longer ethically appropriate according to anatomists. In order to maintain the teaching quality, the Federal University of Juiz de Fora (UFJF) in Brazil, inspired by successful initiatives around the world, created a body donation program; Sempre Vivo. Besides the bureaucratic difficulty faced during its regulation, the implementation of a body donation program requires special attention regarding the religiosity, culture and uniqueness of the city's inhabitants. Informing people can demystify the process, avoid prejudice and increase the number of donors. In this way, an outreach project was designed to publicize Sempre Vivo and raise public awareness. In the first six years, Sempre Vivo reached the mark of 64 registered donors and seven bodies received. The donor's profile corresponds to female (70.3\%), 57 years of age, retired (50.8\%), spiritist (53.1\%) and with 12 years or more of formal education (90.6\%). Considering that the UFJF has not received unclaimed bodies for ten years, the program was considered satisfactory up to this level and, in the future, it may be the exclusive source of anatomical specimens. The description of the creation and the publicizing of Sempre Vivo, the overcome challenges, as well as the donors' profile, may encourage and facilitate the foundation of similar programs in Brazil and abroad.
\end{abstract}

Key words: Body donation, Donors, Anatomy, Health education

Received May 12, 2021; Revised July 23, 2021; Accepted August 10, 2021

Corresponding author:

Alice Belleigoli Rezende (i)

Department of Anatomy, Federal University of Juiz de Fora, Juiz de Fora 36036-900, Brazil

E-mail: alicerezende.ufjf@gmail.com

\section{Introduction}

Human anatomy is the science that studies the structures of the body in all its dimensions and complexities. Due to its relevance for the consolidation of knowledge in the Health sciences, anatomy has become indispensable to undergraduate courses [1-4]. Even with the advent of new methods of teaching in the 21st century, dissection and human speci- 
mens study remain the gold standard for the teaching of anatomy and it is established as a vital component to Health education, considering that it contributes significantly to the acquisition of essential clinical abilities and professional safety [5-8]. Dissabandara et al. [9] have reported that the majority of medical students have a positive perception of dissections. In addition, dissection may have an effect on course performance according to the student's opinion [10]. It is common knowledge among anatomy professors that the teaching of this science must rely on a prepared environment for students' learning, as well as integral anatomical specimens, which should be well-preserved and in a sufficient quantity for the number of students, and they must also provide trustworthy knowledge [11-13]. Besides that, studying using human specimens, alongside ethical education, stimulates respect to the body and sensibility of future healthcare professionals, providing a genuine understanding of the concept of death [14-17].

In Brazil, the regulation for obtaining cadavers for teaching institutions according to the norms of the public authority came to existence in 1992, when a law came into effect supporting the usage of unclaimed bodies within a 30-day period, with the aim of teaching and scientific research [18]. However, with the increasing number of medical schools and Health sciences courses, such a way became insufficient for maintaining an appropriate reserve of bodies at Universities, facing ever-increasing demands for bodies [19]. Furthermore, the development of information technologies has allowed easier identification of bodies, therefore restricting the number of unclaimed bodies addressed to higher education institutions [19].

In addition, although in many countries, including Brazil, the use of unclaimed bodies remains legal, anatomists do not consider this way ethically appropriate to obtain bodies for teaching and research $[19,20]$. The International Federation of Associations of Anatomists (IFAA) recommended in 2012 that only donated bodies should be used for this purpose [21]. The use of unclaimed bodies and the bodies of executed persons was considered ethically controversial, since it uses bodies without consent. This practice was also criticized for discriminating against certain minority groups, such as criminals, poor, homeless people and individuals with mental illness [22, 23].

In this context, an alternative for the maintenance of an anatomical collection at Brazilian universities is to encourage voluntary donations of living donors, an already estab- lished strategy in other countries [19, 24-27]. The creation of programs with this aim answers to the request of individuals who intend to donate their own bodies to research and studies, providing a legal resource to fulfill this wish $[28,29]$. Brazilian law supports the body donation to teaching and research, for scientific or selfless purposes, since $2002[18,30]$.

Body donation is accountable for the totality of bodies obtained in Canada, Chile, the United Kingdom, Japan, and New Zealand, whereas in the United States, Uruguay, Portugal, Korea, and South Africa most of the cadavers used in anatomy laboratories are from donation [23, 27, 31, 32]. In Brazil, there are successful programs in capital cities, such as at the University of São Paulo and at the Federal University of Health Sciences of Porto Alegre (UFCSPA); in the latter institution, the program has been running successfully since 2008 and it currently supplies all the demand in undergraduation $[19,24]$. Organizations working with a private supplier of anatomical material, as described by Wingfield in the United States of America cannot operate in Brazil [33].

The success of the aforementioned initiatives inspired the creation of a similar program at the Federal University of Juiz de Fora (UFJF). However, the implementation of an innovative body donation program in a city demands special attention regarding culture and uniqueness of its inhabitants, whose profiles are different from the ones found in other countries and places, such as large urban centers. The aim of this paper is to report the experience of the creation of the Program of Voluntary Body Donation for Teaching and Research; Sempre Vivo at UFJF and to describe the challenges encountered in the process and the alternatives to overcome them, as well as the profile of registered donors in the first years of operation.

\section{Materials and Methods}

\section{Sempre Vivo program creation}

Juiz de Fora is a non-capital city with a current population of 516,247 according to the 2010 demographic census [34]. The city has a 0.778 HDI (Human Development Index) and stands out in the educational sector. The UFJF and several private universities in Juiz de Fora make it a popular destination for students. UFJF held the 12th position among the Brazilian universities in the 2021 international ranking and some of its courses are considered among the best in Brazil [35].

In 2011, professors at the UFJF Department of Anatomy 
stated that the acquisition of unclaimed bodies for teaching and scientific research had become insufficient for the maintenance of the institution's anatomical collection. There was a progressive decline in the acquisition of bodies connected to an increase in demands for anatomical specimens. In 2007, the Brazilian government allowed a larger number of spots and the creation of new Health courses at federal institutions, which significantly increased the number of students. In this context, it was imperative to find an alternative to keep human specimens available for the teaching of anatomy.

The voluntary body donation emerged as a possibility more suited to ethical principles and already been experienced by other universities [20,36]. In this sense, a team was set up with professors and undergraduates from the Department of Anatomy, aiming to reach the theoretical frame required for the structure of a body donation program. Being so, the UFJF Department of Anatomy started organizing a body donation program Sempre Vivo based on a similar initiative of a Brazilian university located in a capital cityUFCSPA - which was the main reference for the structure and operation of the program [19]. The IFAA guideline was fundamental to follow procedures of the highest ethical standards in order to give donors full confidence in their decision to donate [21].

In 2012, the team started fulfilling the necessary steps for the institutionalization of the program. During this process, Sempre Vivo was approved by different instances at UFJF, until it was regulated by the University in December 2013. The proceeding lasted for about two years due to the dif- ficulties in performing the bureaucratic procedures, which were very particular and unknown to the institution up to that point. In Brazil, despite the body donation having legal protection, the law is very broad and does not define the necessary procedures and documentation, as suggested by the IFAA, which represents challenges in implementing programs for this purpose [21]. Existing body donation programs are the benchmark for creating new ones [37]. Since then, considering this context, the team was also joined by law students and a bioethics specialized professor, responsible for the legal assistance of Sempre Vivo, making it a multidisciplinary program.

\section{Raising public awareness of body donation}

Once Sempre Vivo activities started in January 2014, an outreach project had to be created in order to publicize the program and to reach donors, since body donation still faces many challenges in Brazil and in the world [8]. The first is information; the majority of the population is unaware of the existence of this option and its benefits. Another factor is religious beliefs-most Brazilians follow doctrines in which the concept of death and attachment to the body does not encourage donation [34, 37]. In addition, in Brazil, the main way of obtaining bodies used for teaching and research is still the unclaimed $[23,37]$, usually linked to "forgotten" people, on the margins of society, who have no choice. This generates prejudice and makes it difficult for the dissemination of donation as a noble destination of the body [8], such as it occurs in the United States where body donation is considered a "gift" for teaching and research institutions [38].
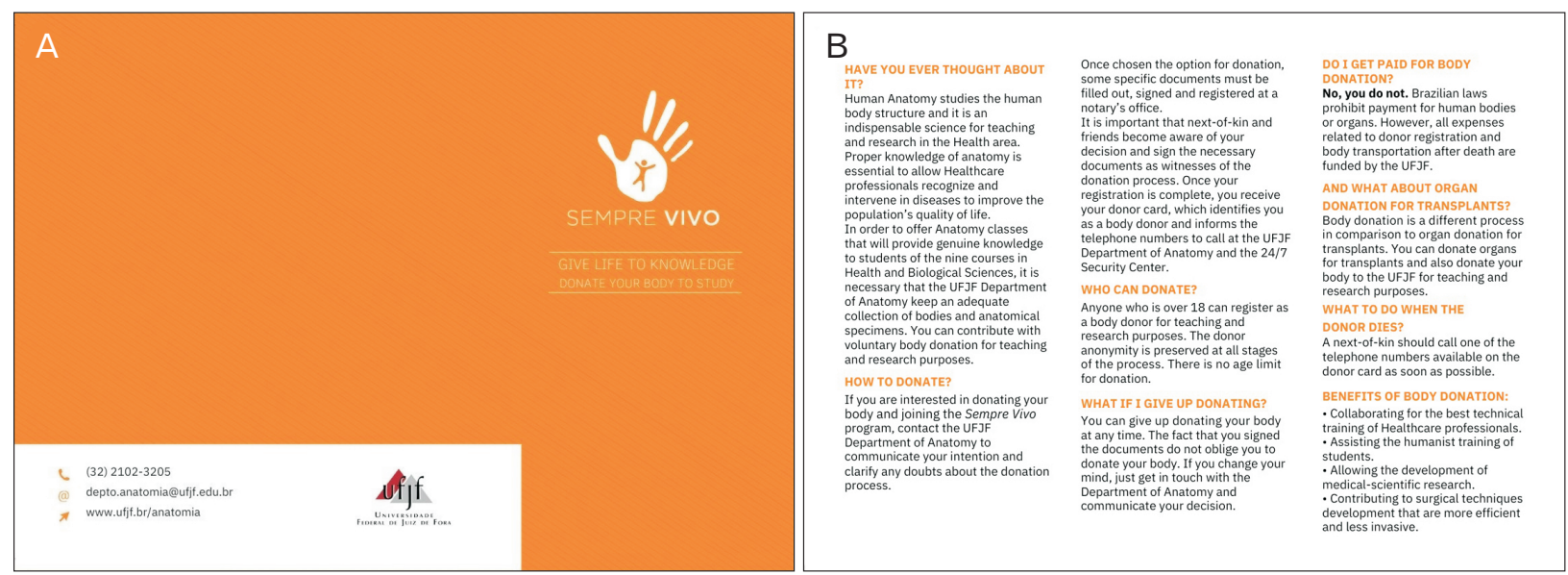

Fig. 1. Sempre Vivo information leaflet. (A) Cover: logo capturing the concept of donation associated with a publicity slogan: "Give life to knowledge, donate your body to study" and how to get in touch with the Department of Anatomy. (B) Inside: information about body donation. 
In this context, the actions of the outreach project aim to maintain a permanent dialogue with the community to publicize the body donation as a real option, and of great importance for the qualified training of Health students. However, conflicts with faith and religious beliefs of individuals are always avoided. In addition, it is highlighted that the donation is a noble destination for the body, and also an altruistic attitude benefiting knowledge. Another objective is to make the academic and local community aware of the fact that body donation is the ethically correct option for maintaining the collection of the Universities [8], which need the participation of the population to preserve the quality of teaching. Currently, there are many legal questions about the use of unclaimed bodies [22, 39].

Since the beginning, the project included professors and undergraduates from the Department of Anatomy and a law professor as well as law students. All have contributed actively in all stages of planning and promotion. The first step of the awareness-raising strategy was the production of a logo associated with a slogan: "Give life to knowledge, donate your body to study" (Fig. 1). The Sempre Vivo logo consists of an image of an open hand (related to the concept of donation) associated with a doll icon (a representative image of a body), with a clear message of valuing body donation.

The second step in the awareness-raising strategy was the online publicization, by showing the program on the Department of Anatomy website (https://www.ufjf.br/anatomia/ doacao-de-corpos-sempre-vivo/) aiming to reach the general population of Juiz de Fora and nearby regions. Regular meetings to discuss the awareness process resulted in the production of an information leaflet and banners to clear communication and publicize the program (Fig. 1). This represented the third step, highlighting important information about body donation, its benefits and how to get in touch with the Department of Anatomy. Parallel to raising the awareness of the general public, specific actions were also developed for the academic community and healthcare professionals, who are the direct beneficiaries of Sempre Vivo, since the bodies obtained are used in its formation and improvement. The program started to be introduced through lectures to all pupils from the Department of Anatomy, a practice encouraged by the IFAA [21], stimulating them to replicate the goals of
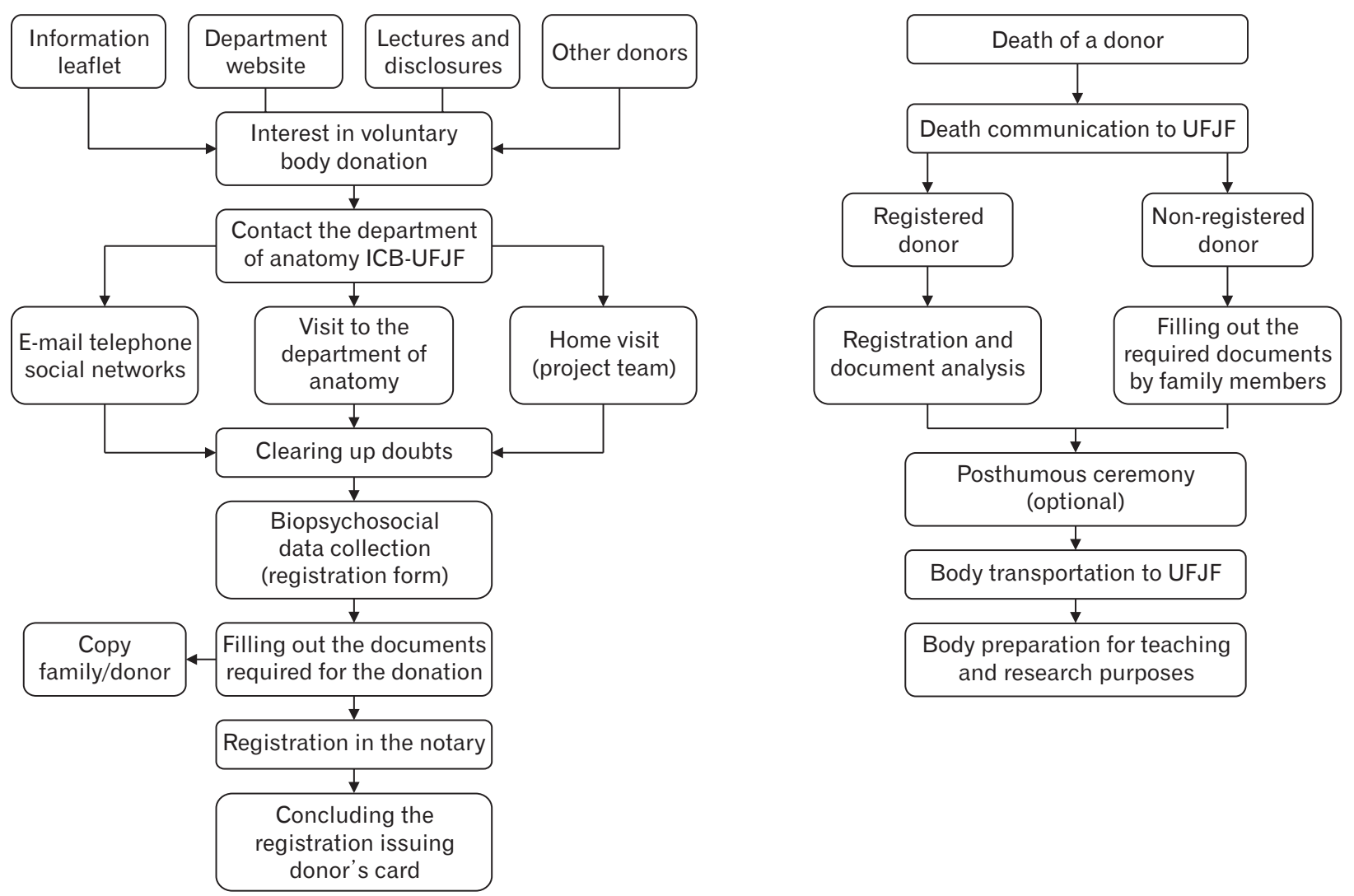

Fig. 2. Flowchart of Sempre Vivo since the donor's access to the program going through the registration procedures until receiving the body. 
the donation to friends and family. Besides that, the Sempre Vivo was also promoted in medical and academic congresses, locally and nationally, offering increasing visibility to the program.

It is important to note that the pupils' participation alongside potential donors has positively impacted on the public awareness. On the other hand, the project has contributed to a broader and more qualified formation of the students involved by encouraging practical learning of teamwork, sharing responsibilities and developing ethical and communication skills.

\section{Sempre Vivo program operability}

As soon as the Sempre Vivo was publicized, people who were interested in donating started to look for the Department of Anatomy. Therefore, a flowchart (Fig. 2) of the procedures for assisting potential donors was created, aiming to standardize actions and certify that all the necessary information and documents were discussed in the process, according to the IFAA recommendations [21]. Right after the first contact with the Department, the potential donor was then invited to learn how the program works by visiting in person. At this moment, the Sempre Vivo team clears up all the donor's doubts and collects biopsychosocial data (registration form). Besides that, the team provides assistance for the correct filling-up of all documents, including consent form, as well as explains about legal procedures which are essential to conclude the application $[19,21]$. The Sempre Vivo team encourages donors to discuss their intentions with their families [20]. In the course of the donor's registration in the program, the next of kin also signs the form, which is considered a good practice in body donation. Donor anonymity is preserved at every stage during the donation process [40, 41].

When it is unfeasible for the donor to go to UFJF, these first contact or general instructions can be performed at home (in which case the team goes to the home of the donor), by telephone or email. After the conclusion of the process, the person receives the Sempre Vivo card, which identifies them as a body donor, being instructed to always carry the card in case of eventful incidents.

If the donor decides to quit the program, he is instructed to get in touch with the Department of Anatomy in order to inform his decision, dismissing any other procedure or justification. After doing so, the registration is deleted from the database. In case the donor comes to pass away, the fam- ily is oriented about the posthumous ceremony, as well as about the necessary procedures for the final transportation of the body to UFJF, with the exception of violent death (such as homicide, suicide and traffic accidents with a victim). In these cases, even if all the documents and forms for donation have been filled and registered in life, the body must remain under custody of the State for analysis and cannot be forwarded to the University [18].

The payment for human material is not ethically acceptable and it is also forbidden by Brazilian laws, so there were no rewards or perks provided to the donors [21, 30]. Body donation is an altruistic gesture, with no direct compensatory benefit to donors, but of great value for education and research in Health sciences. The family that chooses to perform the posthumous ceremonies has to cover the expenses. However, the maintenance costs of the bequest program, preparation and final transportation of the bodies to the Department of Anatomy are supplied by the UFJF.

The program intends to honor the donors by attaching a plaque with their names on the wall of the entrance of the UFJF Department of Anatomy as a special donor memorial. Only donors who have previously agreed to it will have their names on the plaque.

After the arrival of the donated body, the professors of the Department of Anatomy will jointly decide about the use of each body: practical laboratory classes with tutorials for identifying structures using bodies (offered to nine undergraduate courses in Health sciences and Biology); dissection training courses and development of medical-scientific research.

\section{Results}

\section{Sempre Vivo results in six years of operation}

The body bequest program Sempre Vivo, from the conception of the program until May 2020, reached the hallmark of 64 registered donors and seven bodies received (two bodies coming from after-death donation). It is important to emphasize that some members related to the Sempre Vivo have already been registered as donors, although registration is not mandatory for the program team participants.

Some studies have highlighted the fact that the donor profile varies according to the application site [36, 42-44]. The donor profile, specific to each donation program, is important in order to direct strategies to publicize it to the target audience and, consequently, provide positive results. 
The donors' biopsychosocial data collected in the Sempre Vivo registration form were used to draw a profile of the program donors, considering parameters such as sex, age, how the donor came to know about the program, school education, current job situation, income, religious beliefs and faith. The study was approved by the UFJF Research Ethics Committee (no. 2.660.505).

The majority of registered donors are female (70.3\%). The observed average age was $56.5 \pm 14.4(\mathrm{SD})$ years. Among female, it was $53.9 \pm 14.2(\mathrm{SD})$ years, with a minimum age of 19 years and maximum of 89 years. Among male, the average age was $62.7 \pm 13.1$ years (SD), ranging from 33 to 91 years.

In relation to how the donors got to know about the Sempre Vivo program, $25.0 \%$ of them heard from other donors. The second most recurrent means was the website of the Department of Anatomy (18.8\%), which represents a broadly used tool. The other means were less frequent (media, healthcare professionals, information leaflet, among others) as shown in Fig. 3A.

A

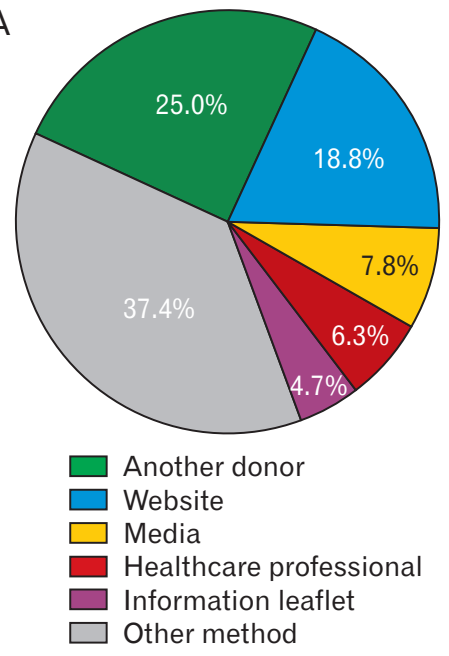

Most registered donors have an average formal education of 12 years or more, with only $9.4 \%$ having lesser education (Fig. 3B). Regarding the current job situation, $42.6 \%$ were active at the time of registration, $50.8 \%$ were retired, $3.3 \%$ were under government benefit and 3.3\% under different circumstances. In this field, two registers did not contain information.

The information of the income was the following: $46.0 \%$ declared earning up to US $\$ 600.00$ per month, including donors with floating income; $38.1 \%$ stated they earn between US $\$ 600.00$ and US $\$ 2,000.00$ a month, and $15.9 \%$, more than US $\$ 2,000.00$ monthly. In Brazil, the minimum wage in formal employment is $\mathrm{R} \$ 1,045.00$ (approximately US \$200.00 a month).

Regarding religious beliefs and faith, more than half of the donors (53.1\%) were Spiritist, 32.9\% had other religious beliefs and $14.0 \%$ were self-proclaimed agnostic or atheists (Fig. 3C).

Considering the results of each year, there were no im-
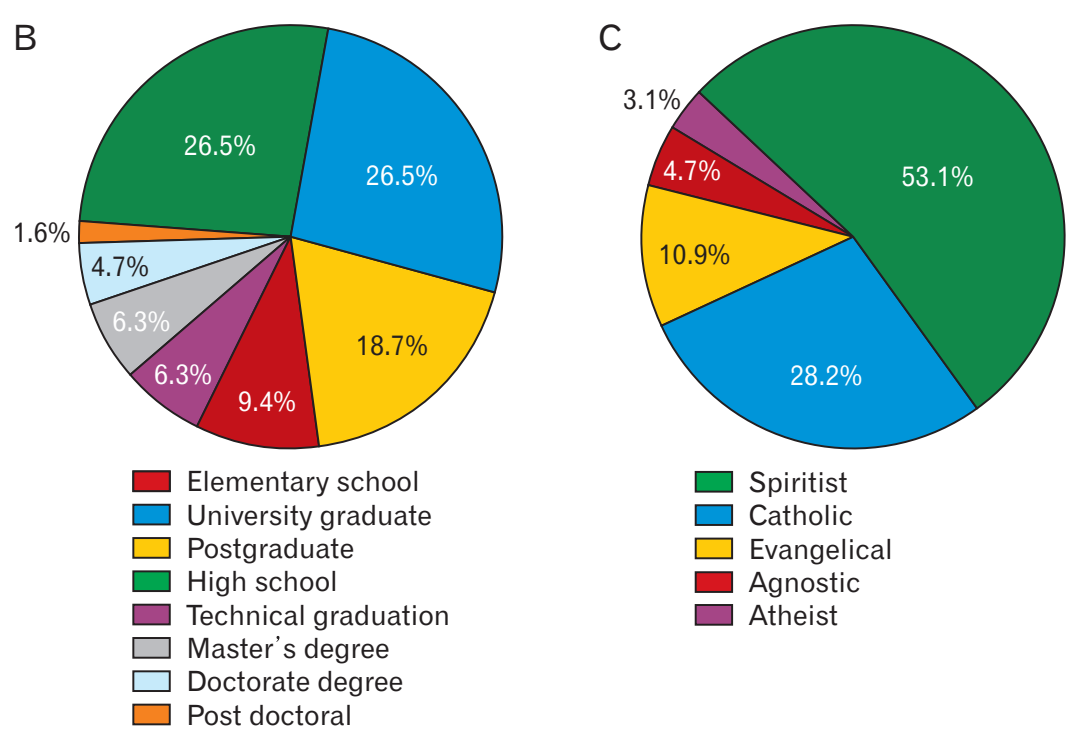

Fig. 3. Sempre Vivo donors profile, regarding (A) how the donor came to know the program; (B) educational level; (C) religious beliefs and faith.

Table 1. Sempre Vivo donor profile per year

\begin{tabular}{|c|c|c|c|c|c|c|}
\hline \multirow{2}{*}{ Donor profile } & \multicolumn{6}{|c|}{ Operating year } \\
\hline & 2014 & 2015 & 2016 & 2017 & 2018 & 2019 \\
\hline Age (yr) & $57.5 \pm 13.0$ & $50.8 \pm 12.5$ & $55.6 \pm 17.4$ & $51.8 \pm 7.8$ & $66.4 \pm 11.4$ & $58.4 \pm 13.9$ \\
\hline Sex (male/female) & $35.7 / 64.3$ & $7.7 / 92.3$ & $40.0 / 60.0$ & $20.0 / 80.0$ & $62.5 / 37.5$ & $11.1 / 88.9$ \\
\hline Program information* & 23.1 (website) & 30.8 (website) & 33.3 (media) & 80.0 (another donor) & 25.0 (another donor) & 44.4 (another donor) \\
\hline Formal education* & 92.3 (>12 years) & 92.3 (>12 years) & 93.3 (>12 years) & 100 (>12 years) & 87.5 (>12 years) & 77.8 (>12 years) \\
\hline Current job situation* & 58.3 (retired) & 66.7 (active) & 60.0 (retired) & 40.0 (retired) & 50.0 (retired) & 55.6 (retired) \\
\hline Income per month* & 46.2 ( $\leq$ US $\$ 600.00)$ & $30.8(\leq$ US $\$ 600.00)$ & 46.7 ( $\leq$ US $\$ 600.00)$ & $40.0(\leq$ US $\$ 600.00)$ & $50.0(\leq$ US $\$ 600.00)$ & 33.3 ( $\leq$ US $\$ 600.00)$ \\
\hline Religious beliefs/faith* & 38.5 (Spiritist) & 61.5 (Spiritist) & 46.7 (Spiritist) & 80.0 (Spiritist) & 50.0 (Spiritist) & 55.6 (Spiritist) \\
\hline
\end{tabular}

Values are presented as mean $\pm \mathrm{SD}$ or $\% .{ }^{*}$ Most prevalent feature. 
portant changes in the donor profile since the creation of the program. However, in the first three years, in relation to how donors got to know the Sempre Vivo program, the most recurrent mean was the website and the media. Since 2017, with the increase in the accumulated number of registered donors, the main mean became another donor (Table 1).

\section{Discussion}

The Department of Anatomy at UFJF attends nine undergraduate programs in the Health sciences and Biology, with a total of about two thousand students per year, which demands a high availability of bodies and anatomical specimens for study. Literature proofs that the contact with natural specimens and the dissection of bodies contributes heavily to the development of ethical and clinical skills which are essential for healthcare professionals, since this is, possibly, the first contact for most students with death $[1,2,6,7,17]$. This experience promotes reflection regarding death, selflessness, respect and generosity, contributing for the personal development of the students, as well as for a humanized professional formation $[8,11,13,14]$.

Traditionally, UFJF receives unclaimed bodies, and its availability has been decreasing progressively throughout the years. Considering that the last arrival of unclaimed bodies predates 2010, the alternative to preserve the supply of bodies was to create a program for voluntary body donation. In addition, with the publication of the IFAA guidelines in 2012, body donation has been highly encouraged, mainly for ethical reasons, and programs have emerged in many cities in different countries [21]. Sempre Vivo started operating in 2014, following the recommendations of good practices towards body donation, in a peculiar scenario. Juiz de Fora differs from the capital cities and large urban centers, where the

Table 2. Summary of the body donation programs discussed above, highlighting the year of foundation and the number of registered donors per year

\begin{tabular}{lcc}
\hline \multicolumn{1}{c}{ University (country) } & $\begin{array}{c}\text { Foundation of } \\
\text { the bequest } \\
\text { program }\end{array}$ & $\begin{array}{c}\text { Donor } \\
\text { registers } \\
(\mathrm{yr})\end{array}$ \\
\hline University of Otago (New Zealand) & 1943 & $>140$ \\
Yonsei University College of Medicine (Korea) & 1992 & $>128$ \\
University of Silesia (Poland) & 2003 & $>113$ \\
University of Bologna (Italy) & 2013 & $>61$ \\
Federal University of Health Sciences of Porto & 2008 & $>29$ \\
$\quad$ Alegre (Brazil) & & \\
Federal University of Juiz de Fora (Brazil) & 2014 & $>10$ \\
\hline
\end{tabular}

main bequest programs in operation in Brazil are located. In this context, it was essential for the team to elaborate an outreach project to raise awareness among potential donors. The Department of Anatomy considers the program satisfactory up to this level and believes that body donation is a feasible alternative and, at the moment, it is the main source for the maintenance of the reserve of bodies at the Institution.

The relevance of donation programs to supply demands of bodies and anatomical specimens to teaching institutions in different countries and regions worldwide is widely evident and validates the current findings [13, 27, 44-46]. At the University of Otago, in New Zealand, the bequest program of the School of Medical Science has been active since 1943, with more than 140 annual registers in the last decades, and also with an approximate reception of 3,000 bodies [45]. In Poland, the donation program at the University of Silesia, in Katowice, counts with approximately 1,250 registered donors since its creation, in 2003 [44]. At the University of Bologna, in Italy, the authors observed an increase from 12 to 431 living donors between the creation of its bequest program in 2013 and the first trimester of 2020 [13]. The number of body donations in Korea increased from 7 to 128 annually at the Yonsei University College of Medicine between 1992 and 2019, reaching a total of 2415 donors [27]. In Brazil, the UFCSPA used to receive about 5 donors registers a year. After the creation of a body donation program, in 2008, this number increased to more than 29 annual registers [19]. Table 2 summarizes the donation programs discussed and shows that the number of annual donor registers is higher in older bequest programs and in more populated regions. In Brazil, UFSCPA's body donation program has three times more annual donor registers than Sempre Vivo, but the population of the city of Porto Alegre is around three times larger. In addition, the UFSCPA's program has been in operation for approximately 12 years $[34,19]$.

On the other hand, unclaimed bodies are still widely used worldwide, including in Brazil. In some countries, it remains the exclusive source of bodies for teaching and research [23]. Since this practice was considered ethically controversial, many anatomists find themselves in a complicated work situation. New discussions addressing this current condition need to occur in the international scientific community, considering the limitations of different realities [20,41].

Regarding the profile of the donors registered on Sempre Vivo, the females are predominant: they correspond to $70.3 \%$, which is higher than the sex difference observed in 
Brazil, where $51.7 \%$ of its inhabitants are female [34]. Similar results were found by Bajor et al. [44] in Poland, by Cornwall et al. [25] in New Zealand, and by Orsini et al. [13] in Italy. In addition, Cornwall et al. [36] showed that in countries like South Africa, Ireland, and New Zealand, female correspond to most of the donors, but they do not differ from the rates that characterize the general population. On the other hand, some studies have registered a very similar proportion between sexs of the donors [42, 47].

The average age of registered donors is approximately 57 years old, which agrees with other studies that present similar results. Orsini et al. [13] found an average age of 59.1 years among registered donors in the University of Bologna, in Italy. In Ireland, the average age registered was around 60 years old; according to the authors, the use of the internet as a means of publicizing the body donation program resulted in a much higher number of younger donors [36]. An important means of accessing Sempre Vivo is the website of the Department of Anatomy, which may partly justify the average age among registered profiles. On the other hand, Park et al. [27] have found a gradual increase in the average age for body donation over 28 years of their bequest program. Jedrzejewski and Ritter [47] found a higher average age, around 82 years, in Rhode Island, USA, which may be associated with a higher life expectancy of the local population [48]. Several studies around the world have also identified a higher average age among donors [25, 27, 42-44]. According to da Rocha et al. [37], this age characteristic might be related to the fact that people over 60 years of age are more likely to consider death and the fate of their bodies.

In addition, the fact that the main way to know Sempre Vivo is through other donors might be associated with efficient and clarifying service to the potential donors and the credibility of the program. The body donation to teaching and research institutions must be carried out according to ethical principles. Transparency in the procedures for donating and handling the body is important for the donor safety, increasing the society contribution and the number of donations. Informed consent and recommendations on the noncommercialization of the body are principles that should guide the body donation $[8,20,21,27]$.

Regarding the level of study among donors, previous studies have shown that individuals associated with donation programs presented a level of formal education of approximately 12 years of study [36, 42, 44]. Most donors of Sempre Vivo presented 12 years or more of formal instruc- tion, supporting this information. This fact might be related to the quality and source of information that the people with a higher education can have access to. In Turkey, the amount of donated bodies meets the need of educational institutions in cities with high educational levels [26]. Furthermore, several researchers reported that body donors tend to have higher educational levels than respective populations [36, 42 , $49,50]$. A study performed in Spain with 2,000 people analyzed the factors that would be associated with organ donation, a very similar scenario. The results have demonstrated that media like television and radio are the ones which allow a wider spread of the information to the population, but a superficial and simplistic approach to the theme does not favor the numbers of people favorable to the donations. In contrast, people with a higher level of education are also exposed to the theme within their institutions, in which organ donation is approached at a deeper level and they are given space for asking questions, which favors acceptance [51]. It is plausible that these considerations can also be applied to body donation, which reinforces the importance of informing donors, and that is already developed in Sempre Vivo. Aiming at reaching the academic and scientific community, educational lectures about body donation are performed for every anatomy student, and the program is published in scientific events, locally and nationally.

In addition, regarding the current job situation of registered donors, the results of Sempre Vivo are similar to those found by Bajor et al. [44] in Poland, where 68\% of all the people registered in the donation program are also retired. Alternatively, McClea and Stringer [43] demonstrated that, in New Zealand, even though the majority of the population is above 60 years old, there is an increasing participation of donors in the active labor market. This characteristic might be associated with an increase of life expectancy around the world in the last decades, as well as with the need of adjustment of retirement systems in several countries, lengthening the workers' activities $[43,52]$.

Furthermore, the income profile of Sempre Vivo donors is similar to the Brazilian population profile of income, according to data from the Brazilian Institute of Geography and Statistics: $42.5 \%$ earn up to US $\$ 600.00$ monthly, $44.5 \%$ between US $\$ 600.00$ and $\$ 2,000.00$, and $13.0 \%$ more than US $\$ 2,000.00$ per month [34]. This profile is corroborated by da Rocha et al. [37] in a major urban center in Brazil. Researchers in other developing countries found a similar result. In Turkey, for instance, the majority of registered donors (39.3\%) 
had a monthly income between 1,000 and 2,000 TL (approximately US $\$ 127-254$ ), while in Thailand $42.8 \%$ of the donors had a monthly income between 10,000 and 30,000 Baht (approximately US $\$ 320-960$ ) [50, 53].

Regarding religion, the current program has noticed that one in two donors to Sempre Vivo is a declared Spiritist. Therefore, Spiritism is the most present religious belief among donors, which differs from the national religious profile. According to the 2010 census, only $2 \%$ of the Brazilian population declared themselves to be Spiritists, while in Juiz de Fora, considered as a reference of this religious belief, 5.4\% of the citizens are adept to Spiritism. In addition, da Rocha et al. [37] assessed the donor profile of a specific region of Brazil where Catholicism predominates with $68.4 \%$ of the population and only $3.6 \%$ is Spiritualist, but $30.2 \%$ of the donors sample evaluated declared themselves Spiritualist, reinforcing the findings of this study. According to Gunderman [54], donating your own body for research and teaching shows great selflessness for the benefit of others. In this context, it is possible then that Spiritism is associated with a higher tendency of body donation, for it is a reincarnationist doctrine that preaches selflessness, dissociation of the body and detachment of the matter $[46,55]$. Other doctrines that also preach the existence of life after death and that the body is only a temporary shelter to the spirit also favor voluntary body donation. In countries where Buddhism is predominant, for example, programs refuse bodies for not having any more physical space [46]. In Korea, the contact of its citizens with the Western culture has reduced the dominance of Confucianism, in which it rejects any form of unnatural disturbance to the body, increasing the number of donors [27, 55]. In Turkey, an interesting finding of Gürses et al. [53] was that religion is both a positive and negative motivational factor, and they argued that given Turkey's different and diverse religions, differences at the donor's profile are also expected.

However, while some religions such as Spiritism make body donation desirable and comfortable for their followers, this decision does not need to be considered contrary to other types of faith and religious beliefs $[46,55]$. The information can demystify the process, show its importance and increase the number of donors from different religions. This reinforces the need for actions to clarify and raise awareness among the population, which was decisive for the Sempre Vivo team to elaborate an outreach project with this objective [8]. Although Juiz de Fora has a larger Spiritist population than other locations in Brazil, this percentage is still very small compared to other religions [34].

The collected data suggest that the prevailing profile among donors for Sempre Vivo is a woman, with higher education, with an average age around of 60 years, and also a declared Spiritist. Some of these traits are not usually found in other body donation programs, and this highlights the fact that the donor profile varies according to their place of application [36, 42-44]. The city of Juiz de Fora presents unique characteristics that might have influenced the implementation and operation of the Sempre Vivo program.

The challenges of creating a body donation program are numerous, but the results are worth it. Some important suggestions can help the process. First, to form a team of human anatomy professors and students who value the body donation for teaching and research. Second, to deeply study the ethical principles involved in body donation; thirdly, to access all information about the legislation that regulates the body donation at the location of the program creation; fourthly, to take advantage of the experience of bequest programs already operating in the host country and abroad; fifthly, to develop a population raising-awareness strategy based on the specific characteristics of their citizens. Furthermore, once the program has been created, it is worthwhile, as soon as possible, to profile the donor and modify the publicization strategy if necessary.

Lastly, there are some limitations in this study, which include the currently short running time of the program and its application in a single university, which restricts the sample numerically. Broader studies, with a larger longitudinal reach, may complement the data and allow this experience to be more faithfully foretold in other contexts. However, in the UFJF scenario, Sempre Vivo is considered an adequate and promising program according to the academic community and the Institution's administration. In the future, it may be the exclusive source of the University reserve of bodies and anatomical specimens.

In conclusion, considering that the UFJF Department of Anatomy has not received unclaimed bodies for ten years and Sempre Vivo has allowed the arrival of seven bodies in six years, body donation represents a viable and ethically desirable alternative for maintaining the supply of anatomical specimens at higher education institutions.

The description of the creation and the publicizing of Sempre Vivo, the challenges encountered in the process and the alternatives to overcome them, as well as the donors' profile, may encourage and facilitate the foundation of new 
similar programs in other teaching and research Institutions, both in Brazil and abroad.

\section{ORCID}

André Gustavo Fernandes de Oliveira:

https://orcid.org/0000-0001-8773-0273

Augusto Ferreira Gonçalves:

https://orcid.org/0000-0003-4372-4116

Júlia Nunes Soares:

https://orcid.org/0000-0001-8198-5259

Letícia Henriques Neto Salgado:

https:/orcid.org/0000-0002-6534-7414

Bruno Silveira Santana:

https://orcid.org/0000-0001-9292-2042

Matheus Venâncio Passos:

https://orcid.org/0000-0002-1478-3646

Juliana Lopes de Oliveira Reis:

https://orcid.org/0000-0002-3931-0968

Gustavo Candiá Arantes:

https://orcid.org/0000-0003-4538-5963

Luís Filipe Sarmento Campos:

https:/orcid.org/0000-0003-2038-0621

Matheus Souza Carvalho:

https:/orcid.org/0000-0003-3677-0368

Lucas Cotrim Furtado da Gama:

https:/orcid.org/0000-0002-9964-5997

Alice Belleigoli Rezende:

https://orcid.org/0000-0002-2584-2496

\section{Author Contributions}

Conceptualization: AGFO, ABR. Data acquisition: AGFO, AFG, JNS, LHNS, BSS, MVP, LFSC, MSC, LCFG, ABR. Data analysis or interpretation: AGFO, AFG, JNS, LHNS, BSS, MVP, LFSC, MSC, LCFG, ABR. Drafting of the manuscript: AGFO, AFG, JNS, LHNS, BSS, MVP, JLOR, GCA, LFSC, MSC, LCFG, ABR. Critical revision of the manuscript: AGFO, JNS, LHNS, BSS, MVP, JLOR, GCA, ABR. Approval of the final version of the manuscript: all authors.

\section{Conflicts of Interest}

No potential conflict of interest relevant to this article was reported.

\section{Acknowledgements}

The authors would like to acknowledge the staff of the UFJF Department of Anatomy, especially the collaborators José Otávio Guedes Junqueira, Valdeci Manoel de Oliveira and Simone Moreira de Macedo, in addition to all the students who participated in the outreach project linked to the Sempre Vivo Program. The authors would also like to thank the collaboration of Law professor João Beccon de Almeida Neto and Anatomy professor Vanessa Neves de Oliveira, founder of the Program. Finally, the authors wish to sincerely thank those who donated their bodies to science so that anatomical research could be performed. Results from such research can potentially improve patient care and increase mankind's overall knowledge. Therefore, these donors and their families deserve our highest gratitude.

\section{References}

1. Ahmed K, Rowland S, Patel V, Khan RS, Ashrafian H, Davies DC, Darzi A, Athanasiou T, Paraskeva PA. Is the structure of anatomy curriculum adequate for safe medical practice? Surgeon 2010;8:318-24.

2. Riederer BM. Body donations today and tomorrow: what is best practice and why? Clin Anat 2016;29:11-8.

3. Farrokhi A, Soleymaninejad M, Ghorbanlou M, Fallah R, Nejatbakhsh R. Applied anatomy, today's requirement for clinical medicine courses. Anat Cell Biol 2017;50:175-9.

4. Bisht B, Hope A, Paul MK. From papyrus leaves to bioprinting and virtual reality: history and innovation in anatomy. Anat Cell Biol 2019;52:226-35.

5. Elizondo-Omaña RE, López SG. The development of clinical reasoning skills: a major objective of the anatomy course. Anat Sci Educ 2008;1:267-8

6. Böckers A, Jerg-Bretzke L, Lamp C, Brinkmann A, Traue HC, Böckers TM. The gross anatomy course: an analysis of its importance. Anat Sci Educ 2010;3:3-11.

7. Kim DH, Shin DH, Hwang YI. Effects of alternate dissection on anatomy learning. Anat Cell Biol 2019;52:69-75.

8. Maghin F, Conti A. Body donation in Italy: an important breakthrough with the new law. Anat Sci Educ 2020;13:800-3.

9. Dissabandara LO, Nirthanan SN, Khoo TK, Tedman R. Role of cadaveric dissections in modern medical curricula: a study on student perceptions. Anat Cell Biol 2015;48:205-12.

10. Greene SJ, Rosen L. Tracking medical student emotionality in relation to whole body dissection and donation. Clin Anat 2021;34:128-42.

11. Ghosh SK. Human cadaveric dissection: a historical account from ancient Greece to the modern era. Anat Cell Biol 2015;48:153-69. 
12. Olejaz M, Hoeyer K. Meet the donors: a qualitative analysis of what donation means to Danish whole body donors. Eur J Anat 2016;20:19-29.

13. Orsini E, Quaranta M, Ratti S, Mariani GA, Mongiorgi S, Billi AM, Manzoli L. The whole body donation program at the university of Bologna: a report based on the experience of one of the oldest university in Western world. Ann Anat 2021;234:151660.

14. Cho MJ, Hwang YI. Students' perception of anatomy education at a Korean medical college with respect to time and contents. Anat Cell Biol 2013;46:157-62.

15. Arráez-Aybar LA, Bueno-López JL, Moxham BJ. Anatomists' views on human body dissection and donation: an international survey. Ann Anat 2014;196:376-86.

16. Hildebrandt $S$. Thoughts on practical core elements of an ethical anatomical education. Clin Anat 2016;29:37-45.

17. Ghosh SK. Paying respect to human cadavers: we owe this to the first teacher in anatomy. Ann Anat 2017;211:129-34.

18. Melo EN, Pinheiro JT. Legal procedures and protocols for use of cadavers in anatomy courses in Pernambuco, Brazil. Rev Bras Educ Med 2010;34:315-23.

19. da Rocha AO, Tormes DA, Lehmann N, Schwab RS, Canto RT. The body donation program at the Federal University of Health Sciences of Porto Alegre: a successful experience in Brazil. Anat Sci Educ 2013;6:199-204.

20. Jones DG. Searching for good practice recommendations on body donation across diverse cultures. Clin Anat 2016;29:55-9.

21. International Federation of Associations of Anatomists (IFAA). Recommendations of good practice for the donation and study of human bodies and tissues for anatomical examination. Plexus 2012;2012:4-5.

22. Jones DG, Whitaker MI. Anatomy's use of unclaimed bodies: reasons against continued dependence on an ethically dubious practice. Clin Anat 2012;25:246-54.

23. Habicht JL, Kiessling C, Winkelmann A. Bodies for anatomy education in medical schools: an overview of the sources of cadavers worldwide. Acad Med 2018;93:1293-300.

24. Simão TRP, Miglino MA, da Silva JB, McManus C, Liberti EA. Implementation of a program of voluntary body donation for anatomical study in the University of São Paulo, Brazil. Int J Morphol 2016;34:1494-501.

25. Cornwall J, Poppelwell Z, McManus R. "Why did you really do it?" A mixed-method analysis of the factors underpinning motivations to register as a body donor. Anat Sci Educ 2018;11:62331.

26. Gürses İA, Coşkun O, Öztürk A. Current status of cadaver sources in Turkey and a wake-up call for Turkish anatomists. Anat Sci Educ 2018;11:155-65.

27. Park HJ, Ahn H, Ki E, Lee JS, Choi Y, Hu KS, Chun YM, Kim HJ. Body donation trends in Yonsei University: a statistical analysis of donor records. Anat Cell Biol 2021;54:59-64.

28. Prakash, Prabhu LV, Rai R, D'Costa S, Jiji PJ, Singh G. Cadavers as teachers in medical education: knowledge is the ultimate gift of body donors. Singapore Med J 2007;48:186-9.
29. Larner SP, Mcquone B, Schober JM, Loukas M, Terrell M. Perceptions of the living dead: an assessment of knowledge and opinions about whole body donation, its process, and willingness to become cadaveric donors in Pennsylvania. Clin Anat 2015;28:442-8.

30. Brazilian Civil Code. Law no 10.406 [Internet]. Brasília: Brazilian Civil Code; 2002 [cited 2020 Jul 15]. Available from: http:// www.planalto.gov.br/ccivil_03/leis/2002/110406.htm.

31. Garment A, Lederer S, Rogers N, Boult L. Let the dead teach the living: the rise of body bequeathal in 20th-century America. Acad Med 2007;82:1000-5.

32. Stott D. Not enough bodies. BMJ 2008;336:0801004.

33. Wingfield HA. Body donation today: a critical comparison of two current practices, and moving into the future. Clin Anat 2018;31:86-9.

34. Instituto Brasileiro de Geografia e Estatística. Demographic census [Internet]. Rio de Janeiro: Instituto Brasileiro de Geografia e Estatística; 2010 [cited 2020 Jul 15]. Available from: https://www.ibge.gov.br/estatisticas/sociais/educacao/9662censo-demografico-2010.html? $\mathrm{t}=$ destaques.

35. U.S. News \& World Report. Best global universities in Brazil [Internet]. New York: U.S. News \& World Report; 2021 [cited $2021 \mathrm{Jul}$ 10]. Available from: https://www.usnews.com/education/best-global-universities/brazil.

36. Cornwall J, Perry GF, Louw G, Stringer MD. Who donates their body to science? An international, multicenter, prospective study. Anat Sci Educ 2012;5:208-16.

37. da Rocha AO, de Campos D, Farina MA, Pacini GS, Girotto MC, Hilbig A. Using body donor demographics to assist the implementation of donation programs in Brazil. Anat Sci Educ 2017;10:475-86.

38. Harvard Medical School. Anatomical gift program [Internet]. Boston: Harvard Medical School; 2021 [cited 2021 Jan 30]. Available from: https://meded.hms.harvard.edu/anatomicalgift-program.

39. Caplan I, DeCamp M. Of discomfort and disagreement: unclaimed bodies in anatomy laboratories at United States Medical Schools. Anat Sci Educ 2019;12:360-9.

40. Jones DG, King MR. Maintaining the anonymity of cadavers in medical education: historic relic or educational and ethical necessity? Anat Sci Educ 2017;10:87-97.

41. Champney TH, Hildebrandt S, Gareth Jones D, Winkelmann A. BODIES R US: ethical views on the commercialization of the dead in medical education and research. Anat Sci Educ 2019;12:317-25.

42. Bolt S, Venbrux E, Eisinga R, Kuks JB, Veening JG, Gerrits PO. Motivation for body donation to science: more than an altruistic act. Ann Anat 2010;192:70-4.

43. McClea K, Stringer MD. The profile of body donors at the Otago School of Medical Sciences--has it changed? N Z Med J 2010;123:9-17.

44. Bajor G, Likus W, Kuszewski P, Kostro K, Łoś A, Kłakus P. "Mortui vivos docent" or who gives his body to science? The analysis of the personal questionnaires of Polish do- 
nors in the Conscious Body Donation Program. PLoS One 2015;10:e0121061.

45. Cornwall J, Stringer MD. The wider importance of cadavers: educational and research diversity from a body bequest program. Anat Sci Educ 2009;2:234-7.

46. Subasinghe SK, Jones DG. Human body donation programs in Sri Lanka: Buddhist perspectives. Anat Sci Educ 2015;8:484-9.

47. Jedrzejewski B, Ritter D. A demographic exploration of whole body donors at the Alpert Medical School of Brown University. R I Med J (2013) 2016;99:37-9.

48. Woolf SH, Schoomaker H. Life expectancy and mortality rates in the United States, 1959-2017. JAMA 2019;322:1996-2016.

49. Lagwinski M, Bernard JC, Keyser ML, Dluzen DE. Survey of cadaveric donor application files: 1978-1993. Clin Anat 1998;11:253-62.

50. Techataweewan N, Panthongviriyakul C, Toomsan Y, Mothong W, Kanla P, Chaichun A, Amarttayakong P, Tayles N. Human body donation in Thailand: Donors at Khon Kaen University. Ann Anat 2018;216:142-51.
51. Conesa C, Ríos Zambudio A, Ramírez P, Canteras M, Rodríguez MM, Parrilla P. Influence of different sources of information on attitude toward organ donation: a factor analysis. Transplant Proc 2004;36:1245-8.

52. World Health Organization. Life expectancy and healthy life expectancy data by WHO region [Internet]. Geneva: World Health Organization; 2018 [cited 2020 Jul 15]. Available from: https://apps.who.int/gho/data/view.main. SDG2016LEXREGv?lang=en.

53. Gürses İA, Ertaş A, Gürtekin B, Coşkun O, Üzel M, Gayretli Ö, Demirci MS. Profile and motivations of registered whole-body donors in Turkey: Istanbul University Experience. Anat Sci Educ 2019;12:370-85.

54. Gunderman RB. Giving ourselves: the ethics of anatomical donation. Anat Sci Educ 2008;1:217-9.

55. Park JT, Jang Y, Park MS, Pae C, Park J, Hu KS, Park JS, Han $\mathrm{SH}, \mathrm{Koh} \mathrm{KS}$, Kim HJ. The trend of body donation for education based on Korean social and religious culture. Anat Sci Educ 2011;4:33-8 